\title{
Research on Transfer and Transformation Mechanism for Technological Results in Applied Colleges
}

\author{
Yaomin Mei \\ Scientific Research Office \\ Zhuhai College of Jilin University \\ Zhuhai, China 519041
}

\begin{abstract}
Colleges are main battlegrounds for technical innovation and main production areas for technical results, and whether the technical results are transformed rapidly or not will greatly influence the implementation of innovative drive development strategy in the country. Applied colleges are required to fully exert their outstanding roles in the transfer and transformation and technical results, pushing the reform of technical results transfer and transformation mechanism, improve technical results transformation benefit distribution system, college functional department linked work mechanism, perfect on(off) duty teachers startup system, results transfer and transformation evaluation system, set technical results transfer and transformation fund, build technical results transfer and transform database and transaction platform, intensify intellectual property service, strengthen technical results talent team construction and promote the implementation of national innovation drive development strategy.
\end{abstract}

Keywords-applied college; technical results; transfer and transformation; mechanism

\section{INTRODUCTION}

In order to deeply carry out the national innovation drive development strategy, Education of Ministry office department issued Action Plan to Promote Technical Results Transfer and Transformation in Colleges (JJTH[2016]115), requiring that colleges should further improve technical results transfer and transformation systems, perfect work mechanisms, encourage and promote college technicians to research and develop new $\&$ hi-tech technologies, transfer technical results, develop new $\&$ hi-tech industry, regulate technical results transfer and industrialization, safeguard benefits of colleges and researchers, fully stir scientific researchers' innovative initiative, enthusiasm and creativity, exert the strength in subject, talent and resource and upgrade capability of serving regional economy and society. Applied colleges are important parts among colleges and universities, they should fully exert their outstanding roles in technical results transfer and transformation, push the reform of technical results transformation mechanism, normalize all links for technical results transfer and transformation, optimize resource allocation, fully stir the enthusiasm of college technicians, promote technical results transformation to actual productivity,

Fund Program: Study on Scientific Research Evaluation Mechanism in Non-governmental Colleges, 2017JZDJ015, 2017 Party Work Program of Zhuhai College, Jiling University upgrade colleges' technical results transfer and transformation level, really intensify colleges' capabilities of serving regional economic and social development, which will play an important role in promoting the implementation of national innovation drive development strategy.

\section{IMPORTANCE FOR COLLEGES'TECHNICAL RESULTS TRANSFER AND TRANSFORMATION}

After opening up, China has achieved huge economic growth which attracts eyeballs of the world, especially in 2010 , China, for the first time, became the second largest economy over Japan. However, the economic growth pattern in China was still extensional and extensive, which mainly relies on resources, capital and cheat labors; and the weakness in technical innovation is one of the major problems faced by the country. To keep the national economy in a sustainable, rapid and healthy development has to depend on technical progress so as to solve problems such as improper industrial structure, poor technologies, low labor productivity and lower economic growth quality and finally speed up the national economy growth changing to benefit type from extension type. On one hand, technical progress means we need to improve scientific research and innovation level, on the other hand, we need to improve the efficiency for technical results transformation. Therefore, to improve technical results transformation in the country especial colleges will play an important role in incubating technological enterprises, speeding up industrial upgrade as well as directly pushing and supporting the economic growth in the country.

On Jan 9, 2006, then-president $\mathrm{Hu}$ Jintao declared at National Technology Conference the technical development goal in coming 15 years: build China a new type country by 2020, making technologies powerfully support the social and economic development. Colleges are main battlegrounds for technical innovation and main production areas for technical results, and whether the technical results are transformed rapidly or not and the ratio of technical results is higher or not will directly determine whether we can achieve the goal that the contribution rate of technical progress will reach $70 \%$ or more. In the meantime, colleges' technical results transformation can promote communications between scientific research and industrial fields, able to incubate hi-tech enterprises, stir technicians' enthusiasm in scientific research 
and promote technical progress, which will play a significant role in building the country into an innovative country.

\section{Status QuO OF TECHNICAL RESUlts TRANSFER AND TRANSFORMATION IN COLLEGES}

The 2017 technical report statistics by Guangdong Technology Department show, there were 17,480 technical contracts signed in 2016 in Guangdong province, totaling 79 billion yuan, of which 76.7 billion yuan related to technologies, the technical contracts of strategic newly rising fields in the province amounted to 63.104 billion yuan in the province, there were 2748 contracts signed by colleges and research institutes, amounting to 1.299 billion yuan, occupying $1.69 \%$ of total technical contract in the province, which shows that the ratio of technical results transformation in colleges is kept lower. For a long time, the difficulty in technical results transformation is a bottleneck blocking the efficient integration of technology and economy. At present, main reasons for the lowered technical results transformation in colleges in the country include: first, researchers are in the lack of activity. Actually researchers are paid highly enough, however, under the market economy, research fields are facing serious outflow of talents. Second, the creativity of technical results and lower transformability. The inadequate supply of technical results, asymmetric information, separation of technical results from market demand, inadequate technique and investment for following up research and development, imperfect mode for technical results commercialization, industrialization and operation, low benefits that researchers get from technical results transformation and so on. Main reasons for the situation are existing laws and policies related to technical results transformation which analyze and design technical results transformation from factors, not touching root causes namely system and mechanism. In order to achieve the integration of technology and economy, it needs to thoroughly break barriers prevent technical results transformation from system and mechanism, focus on the system and mechanism reform related to technical results transformation, intensify the top design and human orientation, solve property relations, decision on labor results value and benefit distribution. In recent years, authorities have released a string of incentive policies to activate researchers, for example, portions of benefits from technical results transformation are used to encourage researchers and increase researchers' earnings steadily.

\section{PERFECT THE SyStem AND MECHANISM OF TECHNICAL RESULTS TRANSFORMATION}

\section{A. Improve Benefit Distribution Systems Related to Technical Results Transformation}

Improve benefit distribution policies related to technical results transformation and safeguard the rights and benefits of all parties related to the technical results transformation. And the rewards and pay to researchers who complete "four technology-related" projects shall follow the benefit distribution policy of technical results transformation. Research departments will take charge of the organization, coordination and instruction of technical results transformation in colleges. The benefits from technical results transformation in colleges will be first distributed to research directors, great contributors and so on, establish details for regulating technical results transformation in colleges, define the benefit distributions to all parties concerned and stir the enthusiasm of all parties concerned to participate in researches.

\section{B. Perfect Linkage Work Mechanism for Functional Departments in Colleges}

Set up and perfect college technical results transformation leadership group, intensify policy, resource arrangement and create an harmonious push mechanism, make sure of task division and responsibility undertakers, urge and instruct colleges in technical results transformation. Establish a technical results transfer and transformation leadership group which mainly consists of group head, president office, teaching affair office, personnel office, financial office, assets office, students office, admission and job office, schools and departments. Draw practicable technical result transformation system and programs, optimize technical result transfer and transformation work procedures, clarify rights and make sure of rules of procedures. Set up and perfect technical results use, disposal policies; build a regulate linked mechanism between functional departments and teaching units, hold a joint meeting every half a year, intensify overall arrangement and efficient connection between college technical innovation policies, layout and reform measures, and offer policy support and safeguard for technical results transfer and transformation in colleges.

\section{Improve Teachers on (off) Post Startup Systems}

Perfect systems related to researchers' on-post part time work, off post startup and return-to-work post, encourage teaching researchers and enterprise technicians for double-way communications. Allow teaching researchers, with post responsibilities fulfilled guaranteed, to use technical results of his (her) or groups for on-post startup or part time work at technical innovation enterprises, cultivate "double-certificate (title)" teaching researchers; allow teaching researchers for startup with pay and post suspended, and the work term shall be three years per stage, two stages at most. Issue Measures About College Teachers for Startup with Pay and Post Suspended, strengthen management on those who conduct on post or off post startup, fully stir teaching researchers' activity and creativity in innovation and startup.

\section{Improve Technical Results Transformation Evaluation Mechanism}

Establish a College Technical Results Transfer and Transformation Evaluation System, and take the technical results transformation as a main reference for individual evaluation, issue technical results transformation policies implementation monitoring and evaluation mechanism and provide supports for adjust and improve relevant policies and measures. Improve information exposure system related to college research project funds and evaluation, increase scientific research management transparency and create conditions for the public for participation and supervision. Create individual scientific research credit archives about 
project application, implementation and evaluation, which will be taken as important basis for project application and evaluation. The units or individuals who are found illegal in academic research or disturbing project reviews will have their qualification restricted to relevant project research or evaluation till cancelled. Those who are found dishonest in scientific research or illegal in academic research will be not allowed to apply for talent selection, annual evaluation, title review, pay increase and so on for three years

\section{E. Set Special Funds for Technical Results Transfer and Transformation}

Applied colleges are required to optimize resources allocation, increase investment, strengthen policy and fun supports for the technical results transfer and transformation construction, give full support and preferential policies in the resources allocation, scientific research facility construction, faculty construction, school-enterprise cooperation and the like, and set special funds for technical innovation guide, technical results transfer and transformation, results transformation base, intellectual property operation and talent cultivation, exert the role of fund leading, promote the technical results transfer and transformation, arrange portions of funds to implement the technical results transfer and transformation. In addition, intensify cooperation with all parties concerned, compete for all levels of financial supports and increase fund sources for technical results transfer and transformation.

\section{Measures to Promote TeChNical Results TRANSFER AND TRANSFORMATION}

\section{A. Create a Database of Technical Results Transfer and Transformation}

Meet regional industrial demand for development, logically plan college discipline construction, focus on new engineering industrial demand for development including high-end new electronic information, bio-medicine, high-end equipment manufacturing, energy saving and environmental protection, new materials, new energy, LED, new-energy vehicles, mobile Internet, could calculation, big data, Internet of Things, intellectual manufacturing, AI, VR, service-based manufacturing, e-commerce, mobile medical service, cloud hospital, Internet safety, intellectual security system and so on, create technical results transformation database, establish codes for important college technical results information collection and service, collect college key technical results, provide information supports for technical results transformation and share scientific research information resources.

\section{B. Build a Transaction Platform for Technical Results Transfer and Transformation}

Build a perfect, professional and commercialized technical results transfer and transformation mechanism, arrange full time personnel at technical management offices, if possible and feasible, build a technical results transfer and transformation transaction platform in charge of college technical results transfer and transformation, construction and management of technical results transfer and transformation section at the college technical website, promote the efficient connection between technical results and enterprises' demand. Strength the information sharing with authorities and enterprises, cooperate with authorities and enterprise to improve the technical transaction online platform, and provide professional service including technical transaction, pricing, information release, online service, bid and auction, technical investment and financing, transformation adverse and the like.

\section{Intensify Intellectual Property Service}

Try best to establish sound cooperation with financial groups such as Business Angel and Startup Investment, and increase investments in technical results transformation projects. Keep close cooperation with domestic organizations and internationally famous transformation institutions, target key industrial technical demands, research and develop or introduce internationally advanced technical results. Actively explore technical results evaluation methods to meet different clients and improve the technical achievements ratios of transformation and success. Facilitate industrial organizations to form technical transformation service standards and codes, build technical transformation service evaluation and credit mechanism, and intensify industrial self regulation management. Perfect the construction of intellectual property transaction platform, and push the efficient connection between technical results and capitals. Build a college incubation intellectual property comprehensive service platform, and provide incubation enterprises with services as intellectual property agency, information, evaluation and operation. Instruct application for patents in industries, guide incubation enterprises to optimize intellectual property layout, create technical cores in enterprises and enhance the market competitiveness. Set up intellectual property risk prevention and dispute settlement mechanism and provide professional intellectual property service for incubation enterprises to compete in international markets.

\section{Strengthen the Construction of Technical Results Transfer and Transformation Talent Teams}

Fully exert the roles of all kinds of innovative talent cultivation demonstration base, and build technical transfer and transformation talent cultivation base relying on relevant institutes, departments and research offices, set technical results transformation courses, set up a high quality technical transfer and transformation faculty team, enhance the capability and level of technical results transfer and transformation talents, carry out engagement systems of technical managers (trial), fully cultivate a great number of professional technical managers who are skilled in technology and finance. Introduce internationally advanced technical manger training courses, cultivate a batch of college technical agent teams which have international views and master international rules; and intensify special training on managers of technical transformation agencies.

Build Internet Plus innovative and startup talent service platform, and provide public service such as technical consultancy, talent plans, technical talent activity, educational training and so on. Push and organize college technical manager coalition, adopt invited lectures, case discussion, case 
investigation, participation in innovation and startup competitions, focus on cultivating comprehensive technical transfer and transformation talents who have mastered technologies and are skilled in marketing.

\section{CONCLUSION}

Through the analysis of the transfer and transformation of $\mathrm{S} \& \mathrm{~T}$ achievements in application-oriented universities, it is found that the mechanism and system of transfer and transformation of S \& T achievements plays a very important role in the transfer and transformation of achievements and the improving the policy of profit distribution of transformation of $S \& T$ achievements can fully mobilize the enthusiasm of researchers and promote the transfer and transformation of $S \&$ $\mathrm{T}$ achievements. The author thinks that colleges and universities should start with the database of transfer and transformation of scientific and technological achievements, trading platform of the transfer and transformation of scientific and technological achievements, the specialized service system of intellectual property and the cultivation of scientific and technological achievements transfer talents to raise the capability of scientific research innovation and promote the effective transfer and transformation of scientific and technological achievements.

\section{REFERENCES}

[1] YFB(2016) File No.118, Opinions of Guangdong People's Government Office Department on Further Promoting Technical Results Transfer and Transformation [Z], 2016.11.18.

[2] JJ(2016) No.3 Several Opinions of Ministry of Education and Ministry of Science and Technology on Strengthening Technical Results Transfer and Transformation in Colleges[Z], 2016.08.17.

[3] Liu Jizhen, Innovate System and Mechanism and Promote Technical Results Transformation in Colleges [J]. Chinese University Technology Transfer, 2016.08.10.

[4] Zhang Huaishui, Enhance the Ratio of Technical Results Transformation and Key to Exert Roles of Colleges as Major Battlegrounds [N]. National Business Daily, 2016.05.30.

[5] Jiang Lidan, He Haiyan, Kang Xiaowei, Innovative Discipline Company System and Mechanism Reform and Promote the Production, Study and Research Results Transformation in Colleges---Typical case of production, study and research of Beijing Institute of Technology Leike Company [J]. Science \& Technology Industry of China, 2015.12.15.

[6] Wang Xuelei, Measures to Deepen Technical Results Transformation System and Mechanism Reform [N]. Anhui Daily, 2014.10.09.

[7] Li Changjian, Wang Xiaoning, Discussion on Importance of Technical Results Transformation in Colleges [J]. Chinese Venture Capital, 2012(26). 